\title{
SURFACE CHANGES AT THE NORTHWEST VATNAJÖKULL GLACIER, ICELAND, DURING THE 2014-2015 BARDARBUNGA ERUPTION
}

\author{
Cristian Rossi $^{1}$, Christian Minet ${ }^{1}$, Eyjólfur Magnússon ${ }^{2}$ \\ ${ }^{1}$ Remote Sensing Technology Institute, German Aerospace Center (DLR), Oberpfaffenhofen, Germany \\ ${ }^{2}$ Institute of Earth Science, University of Iceland, Reykjavik, Iceland.
}

\begin{abstract}
This paper reports a study aimed to detect changes at the northern part of the Vatnajökull glacier, Iceland, by exploiting a stack of Digital Elevation Models (DEMs) generated with Synthetic Aperture Radar (SAR) imagery. The stack is covering the Bardarbunga volcanic system, subject to large topographical variations during the 2014-2015 eruption. In particular, the collapse of the caldera and the restructuring of the glacier, with for instance the formation of new cauldrons, is well represented by the DEM stack, and a quantitative and a geophysical analysis of the results becomes feasible.
\end{abstract}

Index Terms - Vatnaökull, Bardarbunga, TanDEM-X, DEM, glacier changes

\section{INTRODUCTION}

The focus of the paper is the Bardarbunga volcanic system, in the Vatnajökull National Park (Iceland). A small fissure opened up in the Holuhraun plain, situated $48 \mathrm{~km}$ north-east of the caldera, on August 29, 2014, and the eruption lasted a few hours. The main fissure eruption commenced on August 31, 2014, and lasted for 6 months. The Bardarbunga unrest started nearly two weeks before with an intense seismic swarm. This was the largest effusive eruption to occur in Iceland since the 1783-1784 Laki eruption and was characterised by the extrusion of extensive lava flows. A total of $1.6 \pm 0.3$ $\mathrm{km}^{3}$ of lava was produced and an area of $84.1 \pm 0.6 \mathrm{~km}^{2}$ was covered [1]. Through the combined use of InSAR and GPS measurements, the dyke propagation was also modelled and a magma flow rate of $260 \mathrm{~m}^{3} / \mathrm{s}$ was reported [2]. During these months the Bardarbunga caldera slowly collapsed, which is a rare event in Iceland (the previous caldera collapse in Iceland is dated 1875). In this scenario, TanDEM-X remote sensing data is of particular interest [3]. By producing medium-high resolution and accurate elevation models of the caldera, it is possible to evaluate volume losses and topographical changes to increase the knowledge about the ongoing activity.

\section{DATASET}

The TanDEM-X dataset is composed of 5 bistatic acquisitions covering the caldera. The main system parameters are in Tab. 1. The footprint of the data stack and the caldera outline are represented in Fig. 1. The complete description of the test site and the TanDEM-X acquisitions used for this study is presented in [4].

\section{RESULTS}

To evaluate the topographical changes, the DEMs are generated over a fixed geographical grid with spacing of about $6 \mathrm{~m}$ in latitude and longitude [5]. The original interferogram resolution, computed taking into account the independent number of looks and the SAR cell resolution, is about 9 meters.

The DEM differences between the first DEM in the stack (01.08.2014) and all the others are depicted in Fig. 2. The Bardarbunga caldera contour is traced according to the outline sketched in [2]. Fig. 2(a) shows the differential height on the 12th of August. Here, no relevant changes are noticeable since this topographical map represents the elevation differences with a reference time lag of just 11 days and still before the main fissure opened up in the Holuraun plain. The small-scale topographical changes are mainly due to system noise. Instead, the topographical maps in Figs. 2(b), 2(c) and 2 (d) are relevant since respectively showing the topographical changes 47, 58 and 69 days after the main eruption started. The most prominent topographical change is the caldera sub-

\begin{tabular}{c|c|c|c|c|c}
\hline Data & $B_{\perp}[\mathbf{m}]$ & $h_{a}[\mathbf{m}]$ & $\theta[\mathbf{d e g}]$ & $\gamma$ & $h_{\text {err }}$ \\
\hline 01.08 .2014 & 29.7 & 163.3 & 31.4 & 0.86 & 2.3 \\
12.08 .2014 & 31.1 & 156.2 & 31.4 & 0.80 & 2.8 \\
17.10 .2014 & 50.2 & 96.6 & 31.4 & 0.92 & 0.94 \\
28.10 .2014 & 38.2 & 126.8 & 31.4 & 0.92 & 1.2 \\
08.11 .2014 & 57.8 & 84.2 & 31.4 & 0.91 & 0.89 \\
\hline
\end{tabular}

Table 1. Geometrical and processing parameters of the TanDEM-X test site under study. 


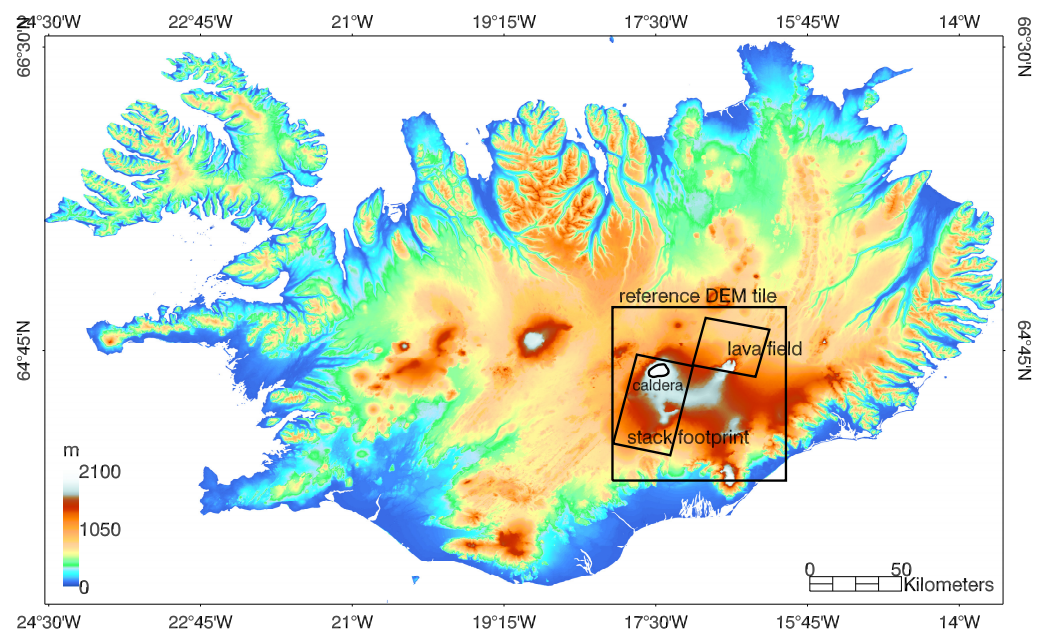

Fig. 1. Footprints of the TanDEM-X acquisitions over the Bardarbunga caldera and the Holuhraun lava field. This figure shows the topography of Iceland and is generated by mosaicking TanDEM-X DEM tiles. The reference TanDEM-X DEM tile used for calibration purposes is also highlighted.

sidence, originated by the collapse of part of the ground above the magma chamber. The considerable depression left in the landscape, with subsidence peaks above $50 \mathrm{~m}$ for the largest time lag in Fig. 2(d), is well visible. The formation of icecap cauldrons at the south-eastern rim of the caldera is also noticeable. Moreover, the differential maps reveal the complete topographical changes over the imaged part of the Vatnajökull glacier. Among them, two accumulations at the eastern Skafta cauldron and at the Grimsvötn volcanic system are remarkable and tagged in Fig. 2(b).

The result of a quantitative study on the caldera subsidence is displayed in Table 2. SAR backscatter is measured by calibrating the amplitude signal and compensating for the local incidence angle. The reference DEM shown in Fig. 1 has been used for this purpose. The mean caldera backscatter is given in the second column of Table 2. The difference between summer and autumn backscatter is due to a different snow liquid water volume (the Vatnajökull glacier can be considered of wet snow type with variable liquid water volume [6]). More in detail, the backscattering coefficient decreases with snow wetness. According to the analysis in [7], the summer backscatter corresponds to a liquid water volume larger than $1\left[\%^{v o l}\right]$, making the TanDEM-X height measure very close to the surface top, according to wet snow dielectric models in the literature (e.g., [8]). In contrary, autumn acquisitions exhibit a backscatter yielding a lower liquid water volume, therefore prone to more substantial penetration issues. An empirical analysis over the large glacier area at the south-east of the caldera, chosen in order to avoid evident topographical changes and marked in Fig. 2(d), reveals a mean difference of $1.26 \mathrm{~m}$. This difference corresponds to a liquid water content smaller than $0.5\left[\%{ }^{v o l}\right]$ [8]. The mean coherence over the caldera given in the third column is in general very high and the relative height error in the fourth column the considerably low. A geophysical interpretation of the results is presented in [4].

A further analysis, serving as validation, is performed by comparing the glacier surface elevation derived with dGPS measurements on November, 11, (standard error: $10 \mathrm{~cm}$ ) and the TanDEM-X measurement taken on November, 08. The GPS reference measure has been taken three days after the TanDEM-X acquisition, and can be considered reliable for validation outside the dynamically changing portions of the glacier (e.g. caldera and cauldrons). The difference between the two measurements is depicted in Fig. 3. As aforementioned, the low liquid water volume of the SAR acquisition yields a certain degree of penetration. The mean difference between reference and TanDEM-X heights is $1.10 \mathrm{~m}$, excluding the caldera and the southern portion of the track, where the terrain slopes yields higher errors. This mean discrepancy confirms then the empirical penetration depth derived by differencing the summer and autumn DEMs. A set of scatter plots, depicted in Fig. 4, can also be analyzed. Fig. 4(a) shows the relationship between the height difference (i.e. proportional to the penetration depth) and the radar backscatter (sigma0). This scatter plot demonstrates that low backscattering implies limited penetration depth due to the increase in water volume content. Fig. 4(b) shows the relationship between coherence and height difference. Although exhibiting very high coherence values, a decreasing trend with respect to the penetration depth is noticeable. This can be associated with a higher volume decorrelation for lower coherence values, bringing to a lower scattering phase center. Finally, Fig. 4(c) shows the relationship between radar backscatter 


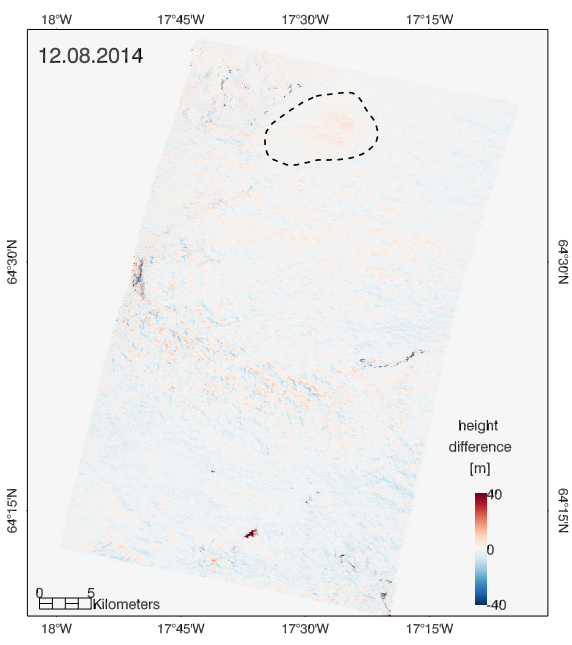

(a) 12.08 .14

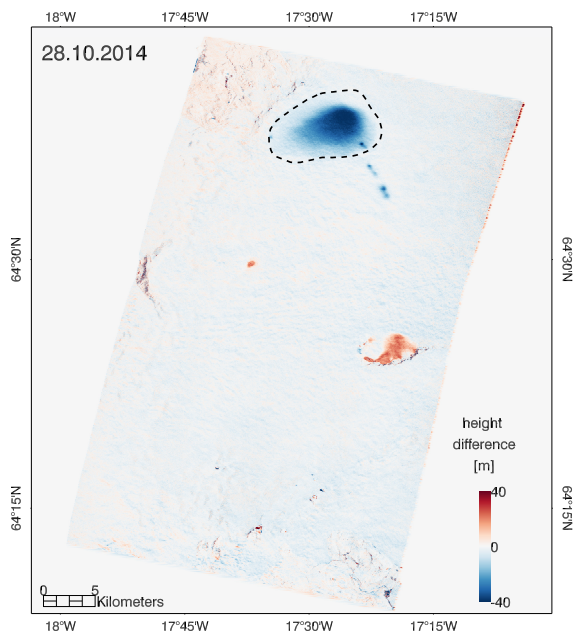

(c) 28.10 .14

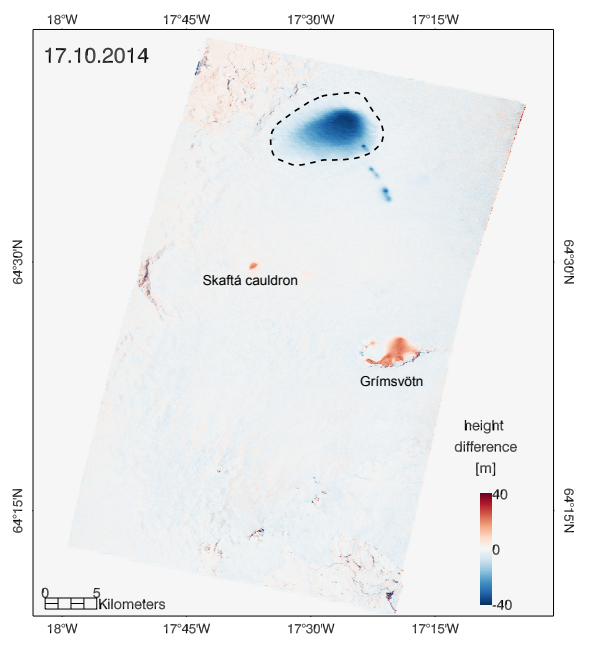

(b) 17.10 .14

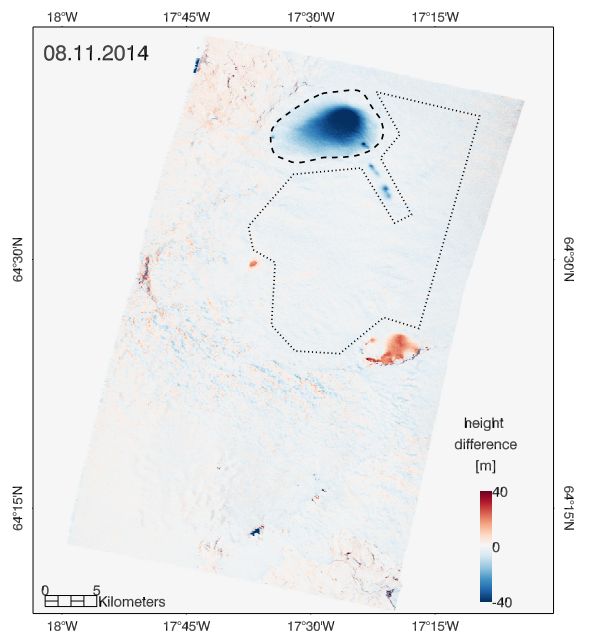

(d) 08.11 .14

Fig. 2. DEM differences relative to the first DEM in the stack (01.08.2014). Bardarbunga caldera is highlighted in all the differences. The dashed area at the south-east of the caldera in $(\mathrm{d})$ is the one used to evaluate the seasonal wave penetration difference.

\begin{tabular}{l|c|c|c|c|c}
\hline Data & $\sigma_{0}[\mathrm{~dB}]$ & $\gamma$ & $h_{\text {err }}[\mathrm{m}]$ & $\Delta \bar{h}_{1.8}[\mathrm{~m}]$ & $\Delta V_{1.8}\left[\mathrm{~m}^{3}\right]$ \\
\hline 01.08 .2014 & $-15.23 \pm 0.86$ & $0.90 \pm 0.03$ & 1.34 & - & - \\
12.08 .2014 & $-15.31 \pm 0.75$ & $0.90 \pm 0.03$ & 1.70 & 0.52 & $0.33 \mathrm{e} 8$ \\
17.10 .2014 & $-9.86 \pm 0.74$ & $0.96 \pm 0.01$ & 0.63 & -13.85 & $-8.81 \mathrm{e} 8$ \\
28.10 .2014 & $-9.75 \pm 0.76$ & $0.96 \pm 0.01$ & 0.55 & -15.13 & $-9.62 \mathrm{e} 8$ \\
08.11 .2014 & $-9.60 \pm 0.77$ & $0.94 \pm 0.01$ & 0.69 & -16.39 & $-10.4 \mathrm{e} 8$ \\
Reference & - & - & 0.67 & -4.53 & $-2.88 \mathrm{e} 8$ \\
\hline \multicolumn{7}{r}{} \\
\hline
\end{tabular}

Table 2. Mean value of relevant parameters computed over the Bardarbunga caldera. The six columns represent, from left to right, acquisition date, mean calibrated SAR backscatter of the master acquisition, mean coherence, mean standard height error, mean DEM difference between and current data, mean volume difference between first stack acquisition and current data. 


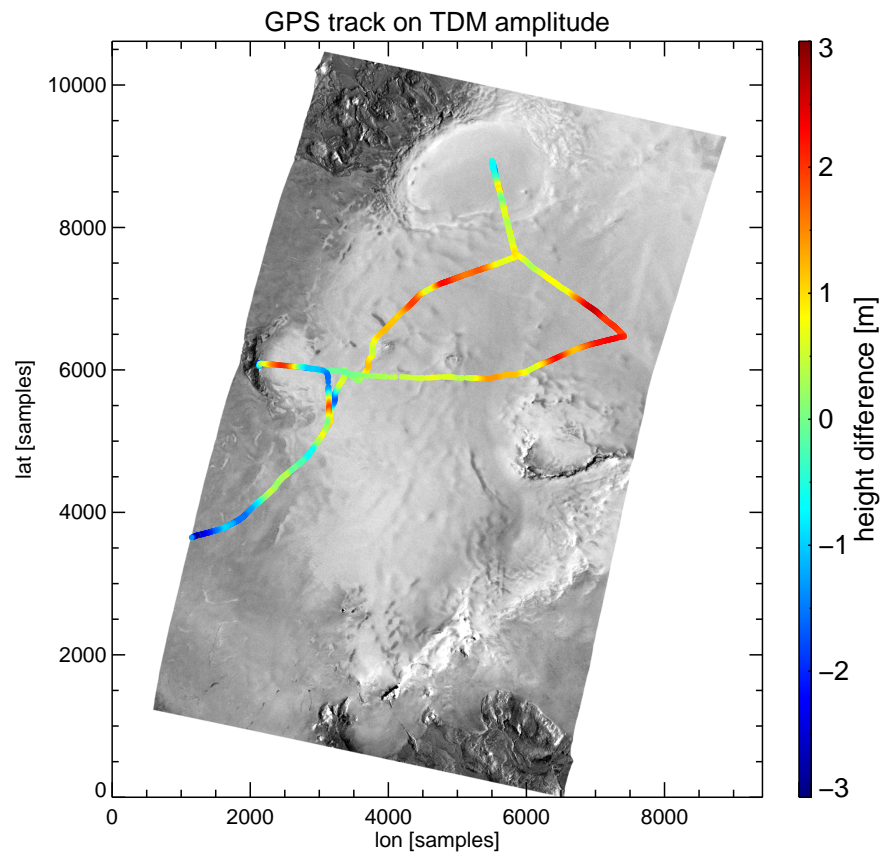

Fig. 3. Height difference between dGPS measurements taken on 11.11.14 and the TanDEM-X measurement taken on 08.11.14. The elevation difference track is overlaid with the TanDEM-X master amplitude.

and coherence. Combining the considerations above, this plot is demonstrating that higher volume decorrelation is linked with lower liquid water content (and viceversa).

\section{REFERENCES}

[1] S. Gíslason, G. Stefánsdóttir, M. Pfeffer, S. Barsotti, T. Jóhannsson, I. Galeczka, E. Bali, O. Sigmarsson, A. Stefánsson, N. Keller et al., "Environmental pressure from the 2014-15 eruption of Bardarbunga volcano, Iceland," Geochem. Perspect. Lett, vol. 1, pp. 84-93, 2015.

[2] F. Sigmundsson et al., "Segmented lateral dyke growth in a rifting event at Bardarbunga volcanic system, Iceland," Nature, no. 517, pp. 191-195, 2015.

[3] G. Krieger, A. Moreira, H. Fiedler, I. Hajnsek, M. Werner, M. Younis, and M. Zink, "TanDEM-X: A satellite formation for high-resolution SAR interferometry," Geoscience and Remote Sensing, IEEE Transactions on, vol. 45, no. 11, pp. 3317-3341, 2007.

[4] C. Rossi, C. Minet, T. Fritz, M. Eineder, and R. Bamler, "Temporal monitoring of subglacial volcanoes with TanDEM-XApplication to the 2014-2015 eruption within the Bárðarbunga volcanic system, Iceland," Remote Sensing of Environment, vol. 181, pp. 186-197, 2016.

[5] C. Rossi, F. R. Gonzalez, T. Fritz, N. Yague-Martinez, and M. Eineder, "TanDEM-X calibrated raw DEM generation," ISPRS Journal of Photogrammetry and Remote Sensing, vol. 73, no. 0 , pp. $12-20,2012$.

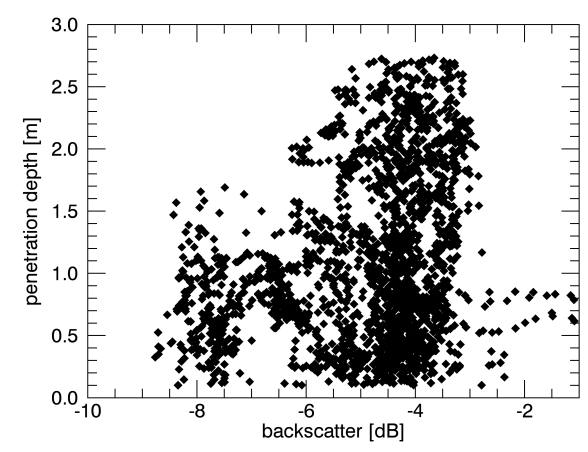

(a) height difference vs backscatter

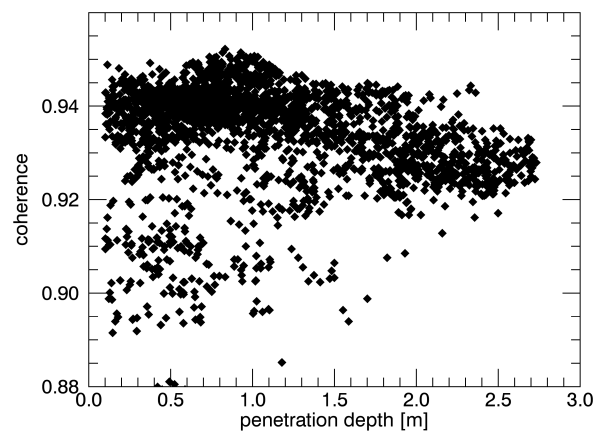

(b) coherence vs height difference

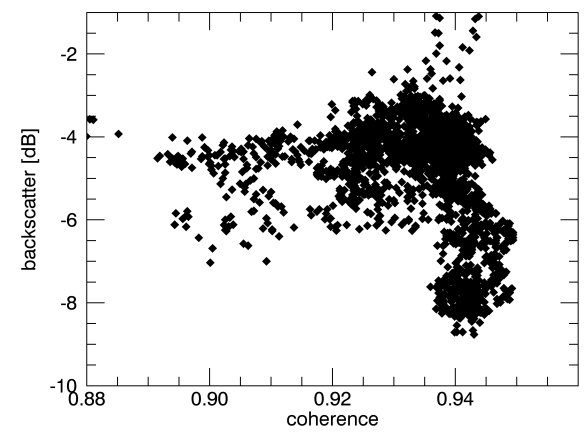

(c) backscatter vs coherence

Fig. 4. Scatter plots related to the 08.11.14 TanDEM-X acquisition.

[6] R. Williams Jr, D. Hall, and C. Benson, "Analysis of glacier facies using satellite techniques," Journal of Glaciology, vol. 37, no. 125 , pp. $120-128,1991$.

[7] W. Stiles and F. Ulaby, "The active and passive microwave response to snow parameters: 1. wetness," Journal of Geophysical Research: Oceans (1978-2012), vol. 85, no. C2, pp. 10371044, 1980.

[8] M. Hallikainen, F. Ulaby, and M. Abdelrazik, "Dielectric properties of snow in the 3 to $37 \mathrm{GHz}$ range," Antennas and Propagation, IEEE Transactions on, vol. 34, no. 11, pp. 1329-1340, 1986. 